\title{
Deep seismic reflection experiment using a dense receiver and sparse shot technique for imaging the deep structure of the Median Tectonic Line (MTL) in east Shikoku, Japan
}

\author{
Tomonori Kawamura ${ }^{1}$, Masazumi Onishi ${ }^{2}$, Eiji Kurashimo ${ }^{1}$, Takeshi Ikawa ${ }^{2}$, and Tanio Ito ${ }^{3}$ \\ ${ }^{1}$ Earthquake Research Institute, University of Tokyo, Yayoi 1-1-1, Bunkyo-ku, Tokyo, 113-0032, Japan \\ 2 JGI Incorporation, Meikei Building, Otsuka 1-5-21, Bunkyo-ku, Tokyo, 112-0012, Japan \\ ${ }^{3}$ Department of Earth Sciences, Chiba University, Yayoi-cho 1-33, Inage-ku, Chiba, 263-8522, Japan
}

(Received October 25, 2002; Revised September 26, 2003; Accepted September 26, 2003)

\begin{abstract}
A seismic experiment was carried out in east Shikoku, Japan, to detect deep reflections across the Median Tectonic Line (MTL), which juxtaposes low-P/T metamorphic rocks with high-P/T metamorphic rocks. Our experiment employed an unconventional technique: sparse shot spacing, a strong energy source (dynamite) and a dense array of seismometers. The above specifications produce only single fold coverage without common midpoint (CMP) stacking. Nevertheless, the reflection profile provides essential information on the deep structure of the MTL, of other major faults, and of the Moho in east Shikoku. On the MTL, this profile is the first to delineate the MTL from the surface to about $12 \mathrm{~km}$ depth. The following three factors were essential to the success of our experiment. First, the receiver interval was sufficiently small to provide horizontal resolution that was able to detect deep reflectors. Second, the simple crustal structure does not require CMP stacking to enhance data quality. Third, a thin weathering layer at the surface reduced the attenuation of seismic waves and minimized the generation of the surface waves that often obscure deep reflectors. In these conditions, the technique can be an effective means of probing the deep crust while substantially reducing survey costs.
\end{abstract}

Key words: MTL, seismic reflection, single fold, Setouchi volcanic rocks.

\section{Introduction}

Seismic reflection profiling, once used primarily for oil exploration, has become a powerful tool for investigating deep crustal structure. Its use, however, might be too expensive if the target is restricted to a local area. In contrast to wideangle reflections, the observation of near-vertical reflections within short source-receiver offsets suggests profiles of short length may be cost-effective. Klemperer et al. (1986) identified prominent, near-vertical reflections from the Moho beneath Nevada on a single-fold profile, yet the reflections were not obvious on the 48-fold CMP stacked data. Fuis et al. (1995) revealed crustal-scale duplexing of the Brooks Range, Arctic Alaska, using near-vertical reflections at as much as $12 \mathrm{~s}$ two way travel time (TWT) both on a low-fold stacked section and on a single-fold section obtained with a relatively dense receiver interval $(100 \mathrm{~m})$ and a shot spacing of $8 \mathrm{~km}$. Thus, a seismic reflection profile can be successful without CMP stacking if recorded under the right conditions. Singlefold profiling allows us to minimize the number of shots and contributes to substantially reducing the survey cost.

A seismic experiment was carried out across the Median Tectonic Line (MTL) in east Shikoku, Japan, in 1999 (Fig. 1) to detect near-vertical, deep reflections using a single-fold mode of recording. Our experiment consisted of a combination of a highly dense receiver array ( $50 \mathrm{~m}$-interval) but only

Copy right(C) The Society of Geomagnetism and Earth, Planetary and Space Sciences (SGEPSS); The Seismological Society of Japan; The Volcanological Society of Japan; The Geodetic Society of Japan; The Japanese Society for Planetary Sciences. two shots at both ends of a 12-km-long seismic line, resulting in a single-fold reflection profile. The experiment was successful in revealing the deep structure of the MTL and in detecting prominent reflectors down to Moho depth.

In this paper, we demonstrate that our dense receiver and sparse shot technique can cost-effectively delineate the deep structure of a major crustal fault (MTL) which was previously detected in a more conventional shallow reflection profile (Ito et al., 1996).

\section{Geologic Outline of East Shikoku}

\subsection{Surface structure}

The surface structure of Southwest Japan is characterized by the along-arc zonal arrangement of several geologic belts. In east Shikoku the typical arrangement includes the Ryoke, the Sambagawa, the Chichibu, and the Shimanto belts (Fig. 1; Geological Survey of Japan, 1977).

The Ryoke belt is composed dominantly of an early Late Cretaceous granite (Ryoke granite) and subordinately of low-P/T metamorphic rocks associated with intrusion of the granite. The metamorphic rocks have their origin in Jurassic accretionary complexes. The Izumi group, consisting of Late Cretaceous thick marine sedimentary rocks, unconformably covers the granite. The Sambagawa belt is characterized by high-P/T metamorphic rocks that are derived from a Cretaceous accretionary complex. Because the Chichibu belt is also composed of a Jurassic accretionary complex, it is considered an outlier of Jurassic accretionary complexes derived from north of the MTL (Isozaki, 1996). The Shi- 


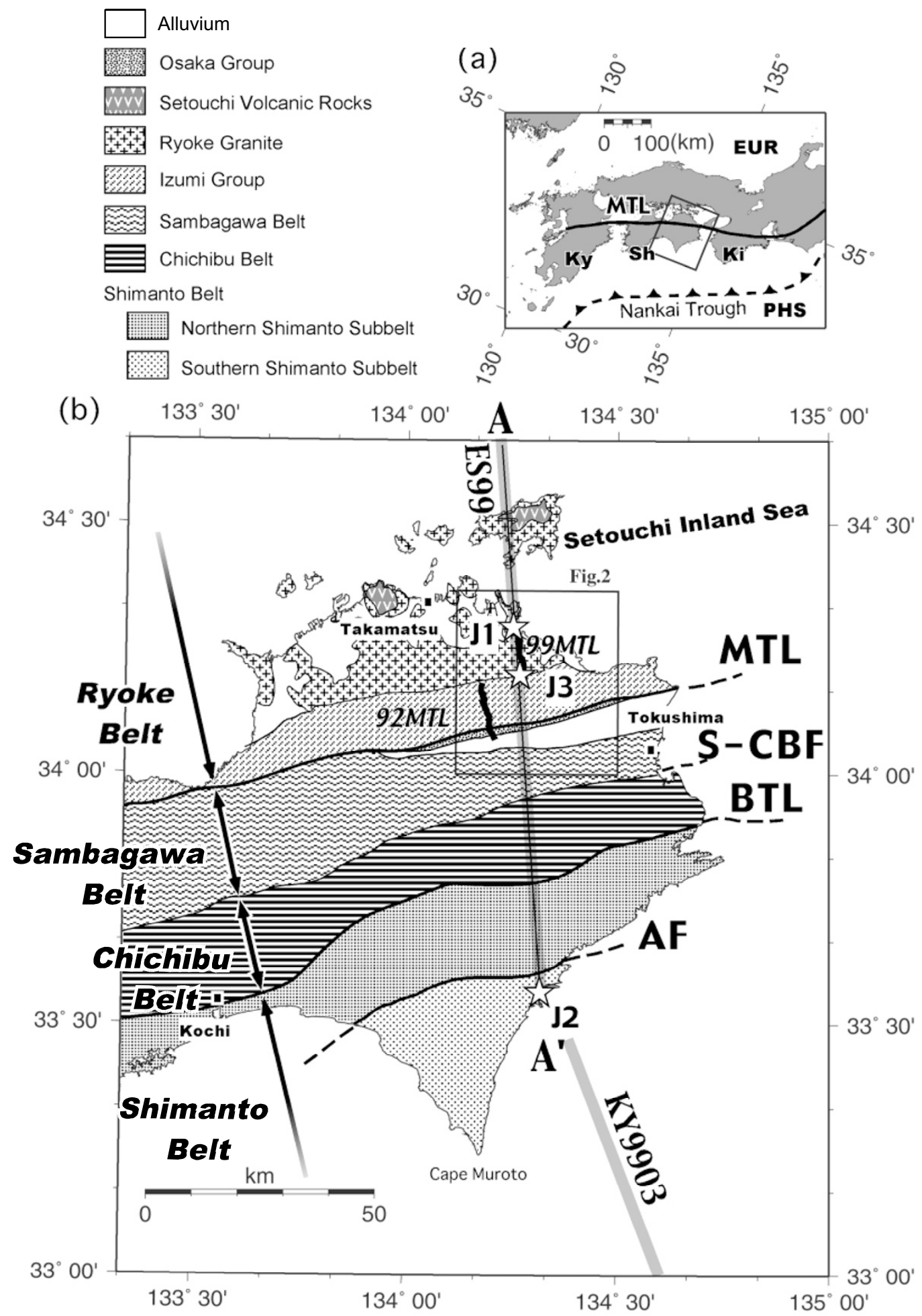

Fig. 1. (a) Plate system around southwest Japan. PHS: Philippine Sea Plate, EUR: Eurasia Plate, MTL: Median Tectonic Line, Ky: Kyushu Island, Sh: Shikoku Island, Ki: Kii Peninsula. (b) Geologic map of east Shikoku (Geological Survey of Japan, 1995) and seismic lines. S-CBF: Sambagawa-Chichibu boundary fault, BTL: Butsuzo Tectonic Line, AF: Aki fault. Heavy solid lines are seismic lines of 92MTL (Ito et al., 1996) and 99MTL (this study). Shaded lines ES99 and KY9903 correspond to the seismic lines of Kurashimo et al. (2002) and Kodaira et al. (2000), respectively. J1, J2 and J3 indicate dynamite shot points of the JAMSTEC deep seismic investigation. A-A': Cross section line of Fig. 7.

manto belt is divided into the Northern and Southern subbelts. The former is composed of a Cretaceous accretionary complex called the Northern Shimanto group, and the latter is a Paleocene to early Miocene accretionary complex called the Southern Shimanto group. These belts are bounded by major boundary faults: the Median Tectonic Line (MTL) be- tween the Ryoke and the Sambagawa belts, the SambagawaChichibu boundary fault (S-CBF) between the Sambagawa and the Chichibu belts, the Butsuzo Tectonic Line (BTL) between the Chichibu and the Northern Shimanto belts, and the Aki fault (AF; Katto, 1961) between the Northern Shimanto and the Southern Shimanto subbelts. The present subduc- 


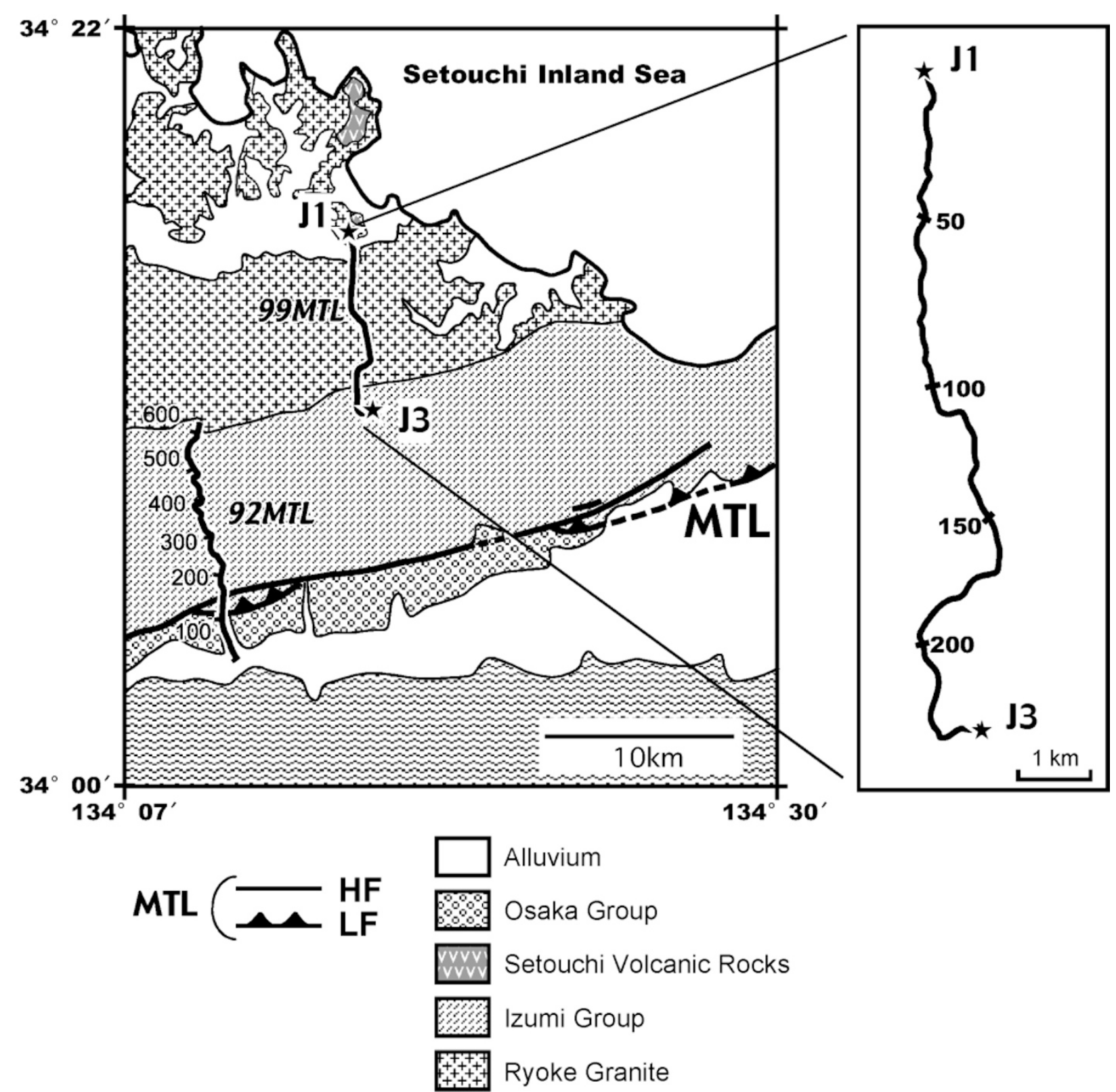

\section{Sambagawa Metamorphic Rocks}

Fig. 2. Geologic map around the MTL and seismic lines 92MTL and 99MTL with location numbers. Surface traces of the MTL are after Hasegawa (1992), Mizuno et al. (1993) and Tsukuda et al. (1982).

tion zone of the Philippine Sea Plate runs along the Nankai trough about $100 \mathrm{~km}$ off Cape Muroto.

This zonal arrangement has been slightly modified by the Setouchi volcanic rocks and the Osaka group. The Setouchi volcanic rocks are characterized by andesitic and rhyolitic rocks of 15 to $13 \mathrm{Ma}$ (Tatsumi et al., 2001), which cover the Ryoke belt in and around the Setouchi Inland Sea. The Osaka group is composed mostly of late Pliocene to middle Pleistocene, non-marine fluvial deposits distributed widely in the Ryoke belt and partly in the Sambagawa belt. Recent activity on the MTL juxtaposes the Izumi Group in the Ryoke belt with the Osaka group.

\subsection{Target of our experiment}

Most major boundary faults in the study area are thought to dip northward (e.g., Taira et al., 1992). The deeper part of the BTL is estimated to be subhorizontal from structural analysis (Murata, 1982). However, these interpretations are based mainly on surface geology, not on geophysical imaging of subsurface structures. Strictly speaking, the subsurface geometries of the major boundary faults are unknown. Only the MTL has received attention from geophysicists, with exploration of its deep structure made in Kyushu (Yusa et al., 1992), Kii (Yoshikawa et al., 1992; Kasahara et al., 2000; Kawamura et al., 2001), and Shikoku (Ito et al., 1996). The results of these surveys indicate that the MTL dips at less than $45^{\circ}$ from the surface to several $\mathrm{km}$ depth, and that the active high-angle faults ("HF" in Fig. 2) splay off of the lowangle MTL ("LF") near the surface (Ito et al., 1996; Kawamura et al., 2001). Although the structure of the MTL deeper than several $\mathrm{km}$ remains unclear from these surveys, the exis- 


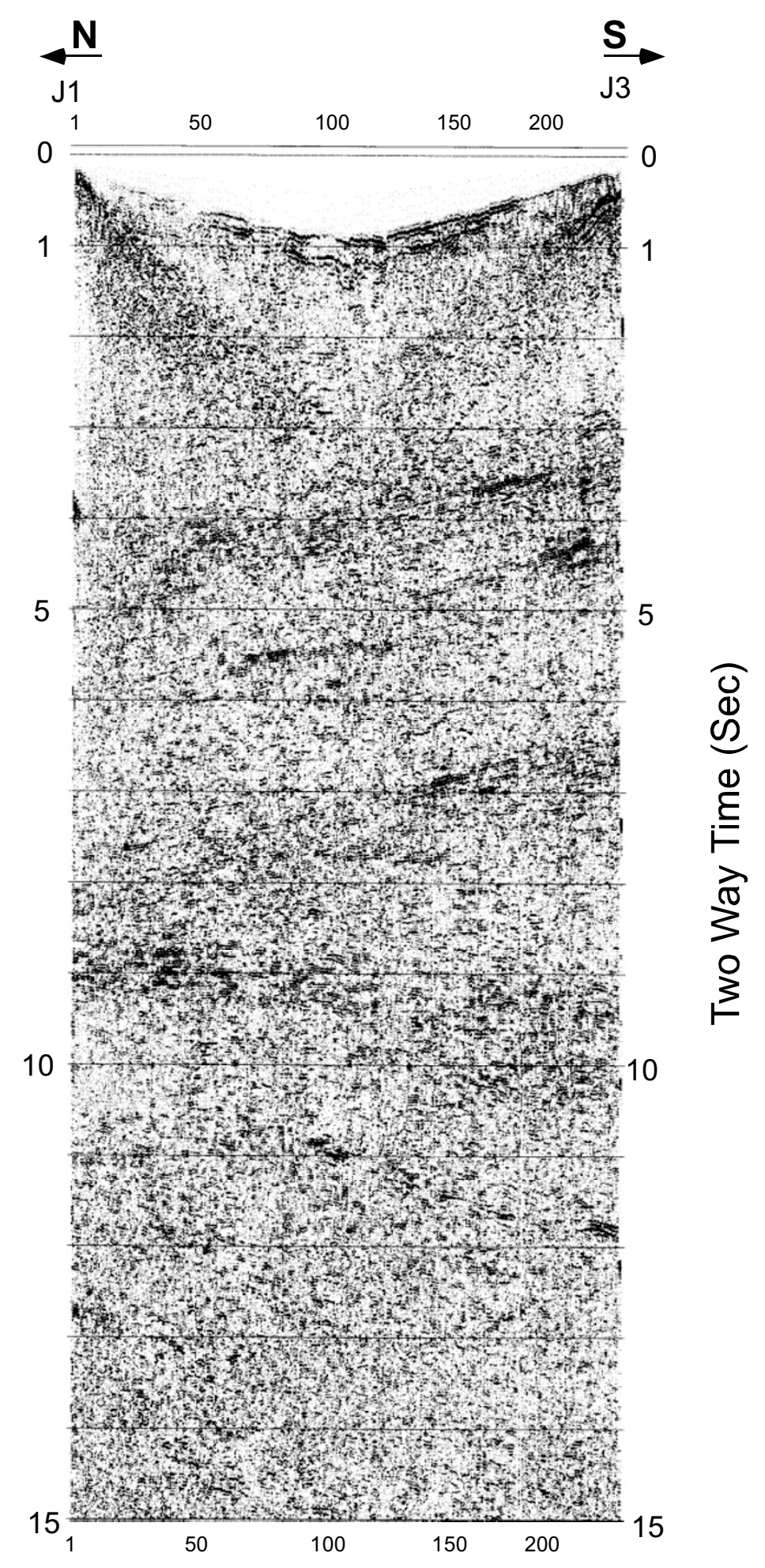

Fig. 3. CMP based single-fold seismic section. $0 \mathrm{~s}$ (two way time) corresponds to the surface of the seismic line.

tence of prominent reflectors from the MTL in each previous survey indicates the potential of detecting its deeper structure within a seismic survey. Thus, the deep extension of the MTL was the principal target for our experiment.

\section{Seismic Reflection Experiment}

\subsection{Field measurement}

Our deep seismic experiment, 99MTL, was designed in conjunction with the JAMSTEC (Japan Marine Science and
Technology Center) deep seismic investigation across southwest Japan (Fig. 1). Our N-S trending, 12-km-long seismic line runs mainly on the Ryoke granite in the Ryoke belt and reaches onto the Izumi group at its southern end. The previous seismic line 92MTL (Ito et al., 1996) begins about $10 \mathrm{~km}$ west of the southern end of 99MTL (Fig. 2).

Our experiment has unconventional acquisition parameters (Table 1). It is focused on detecting near-vertical, deep reflections along a short-offset seismic line. The receiver in- 
Table 1. Acquisition parameters.

\begin{tabular}{ll}
\hline Seismic Source & No. of shot point: $2(\mathrm{~J}-1$ and J-3) \\
& Dynamite: $500 \mathrm{~kg}(\mathrm{~J}-1), 100 \mathrm{~kg}(\mathrm{~J}-3)$ \\
& Shot hole depth: $70 \mathrm{~m}(\mathrm{~J}-1), 30 \mathrm{~m}(\mathrm{~J}-3)$ \\
& Frequency: $8 \mathrm{~Hz}$ \\
& Phones/Station: 9 \\
& Station interval: $50 \mathrm{~m}$ \\
& No. of stations: 242 \\
& GDAPS-4 Digital telemetry system \\
& Sample rate: 4 msec \\
& Record length: $60 \mathrm{sec}$ \\
& No. of channels: 242 \\
\hline
\end{tabular}

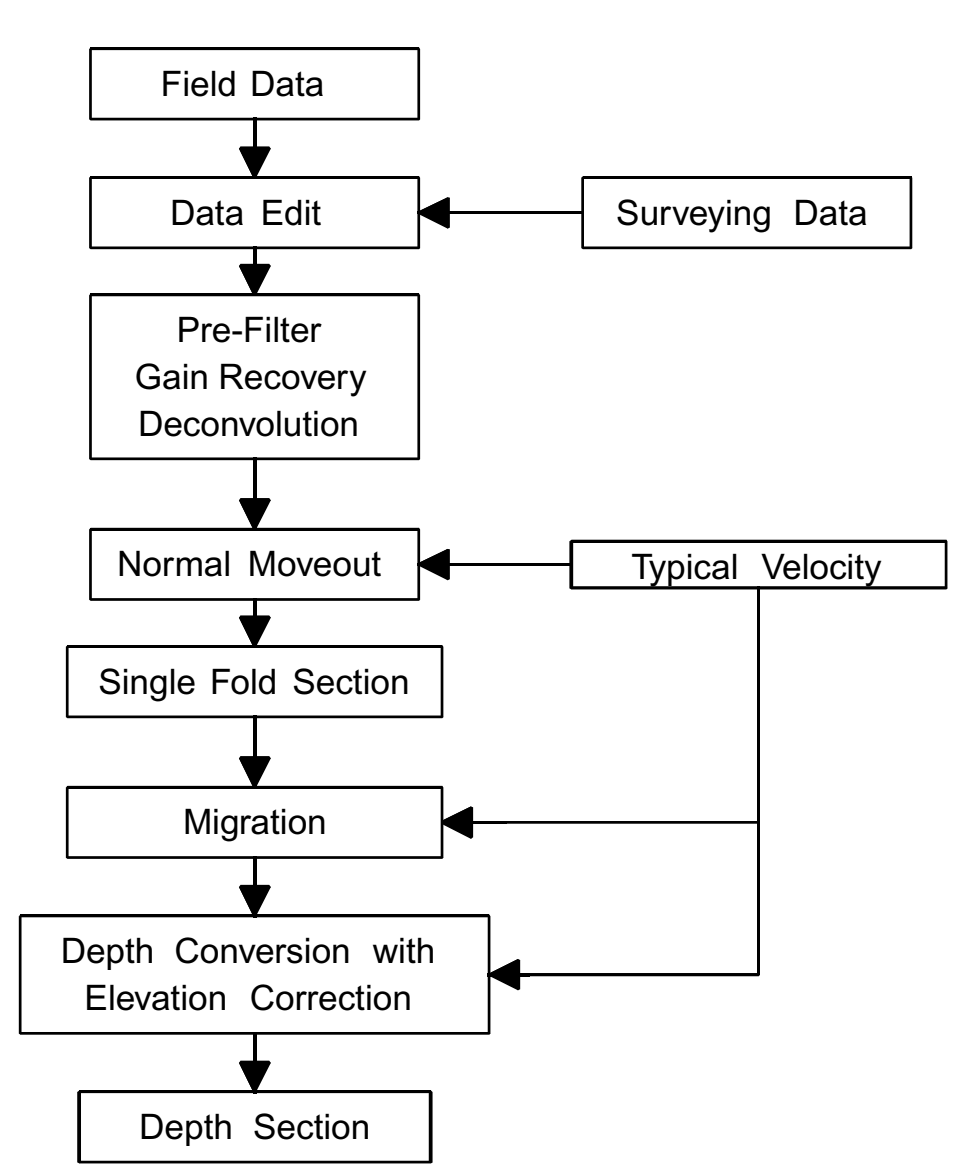

Fig. 4. Flow chart of data processing for seismic reflection analysis.

terval was as small as $50 \mathrm{~m}$, with 242 stations located along the line. Only two shot points were used, J1 (500 kg) at the northern and $\mathrm{J} 3(100 \mathrm{~kg})$ at the southern ends of the line. This geometry results in a single-fold reflection profile. A digital telemetry seismic recording system (GDAPS-4 recording instrument of JGI) was used for collecting the seismic data. The data were digitized on-site by remote units at every fourth-receiver station, and were rapidly transmitted to a central recording unit.

Seismic records for the $\mathrm{J} 1$ and the $\mathrm{J} 3$ shots have good quality (Fig. 3). In addition to first breaks, several deep reflections are clearly identified. Dominant reflections at $3.5 \mathrm{~s}, 4.5 \mathrm{~s}$ and $6.5 \mathrm{~s}$ two way traveltime are north-dipping, but the deeper reflectors that appear from $9.0 \mathrm{~s}$ to $12 \mathrm{~s}$ are south-dipping. Thus, we recognize that each shot provided enough energy to detect deep reflectors.

\subsection{Data analysis}

A single-fold reflection profile was constructed according to the data processing flow shown in Fig. 4. Mid-points of all seismic traces were projected on a straight line connecting the J1 and the J3 shot. Because standard velocity analyses based on common midpoint (CMP) gathers are not suitable for shot gathers, we used velocity information obtained by previous works for the normal moveout correction (NMO). The shallow velocity structures are estimated by the 92MTL data (Ito et al., 1996) with consideration that the most of the seismic line lies on the Ryoke granite without sedimentary cover (Fig. 2). For deeper part of the crust, $2 \mathrm{~s}$ TWT 


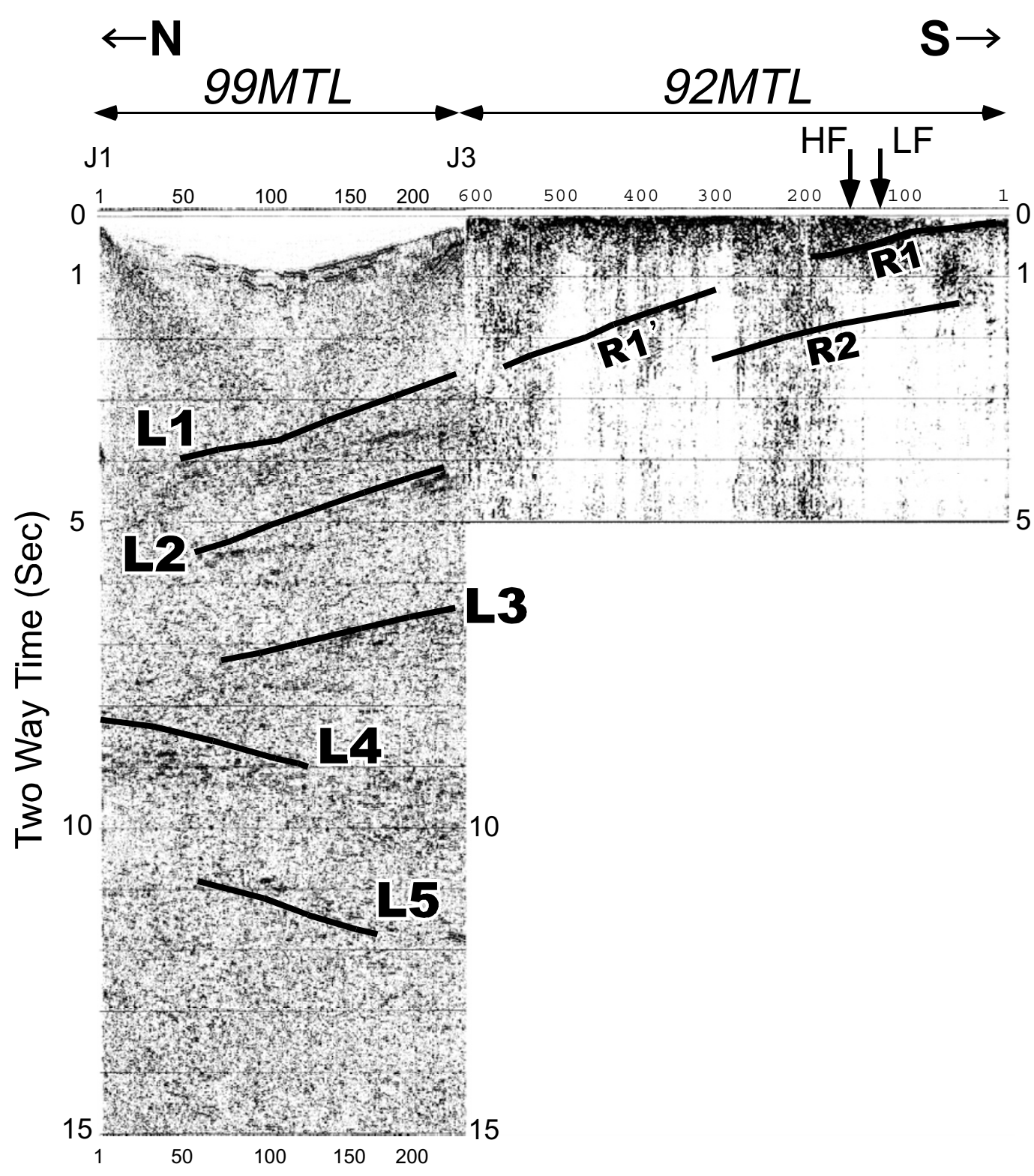

Fig. 5. Major features of the integrated, unmigrated time section of 99MTL (northern half) with 92MTL (southern half). See text for explanation of L1 to L5. See Ito et al. (1996) for explanation of R1, R1' and R2.

or more, we used the velocities that were estimated by the refraction survey (Kurashimo et al., 2002). Only elevation static corrections were applied because the weathering layer is too thin to require subsurface static corrections.

Inspection of the single-fold unmigrated section (Fig. 5, left) reveals five prominent reflections, L1 to L5. Northdipping L1, L2, and L3 occur at 2.6 to $3.7 \mathrm{~s} \mathrm{TWT,} 4.0$ to $4.5 \mathrm{~s}$, and 6.3 to $7.1 \mathrm{~s}$, respectively. South-dipping L4 and L5 lie at 8.5 to $10.3 \mathrm{~s}$ and at about $11 \mathrm{~s}$, respectively. Migration was carried out so as to preserve the image of dipping events that migrated beyond the end of the seismic line. Finally, a merged migrated depth section was produced with 92MTL (Fig. 6). Because, our data do not have full diffraction curves, the dip of angle of the prominent reflectors in the migrated section can be higher than that of real reflectors.

\subsection{Interpretation}

Reflector L1 correlates with R1 through R1' (92MTL), and reflector L2 with R2 (Fig. 5). As R1 and R2 corre- spond to the upper boundaries of the Sambagawa metamorphic rocks and the Northern Shimanto group, respectively (Ito et al., 1996), L1 and L2 are interpreted as representing these boundaries.

The comparison of this profile (Fig. 5) with a previous profile across the Kii peninsula $100 \mathrm{~km}$ to the east (Kasahara et $a l ., 2000)$ suggests that L3 corresponds approximately to the boundary between the Northern and the Southern Shimanto subbelts, that is, the Aki fault at depth. The laminated zone under L3 corresponds to the alternation of mud and sand layers in Southern Shimanto subbelt. Deeper parts of major north-dipping boundary faults, MTL, BTL and AF, are identified with L1, L2 and L3, respectively.

South-dipping deeper reflectors L4 and L5 are the upper and the lower boundaries of a laminated zone (Fig. 6). According to the seismic refraction study by Kurashimo et al. (2002) along A-A' in Fig. 1, the zone between L4 and L5 has a seismic velocity of $6.6 \mathrm{~km} / \mathrm{s}$ and L5 approximately corre- 


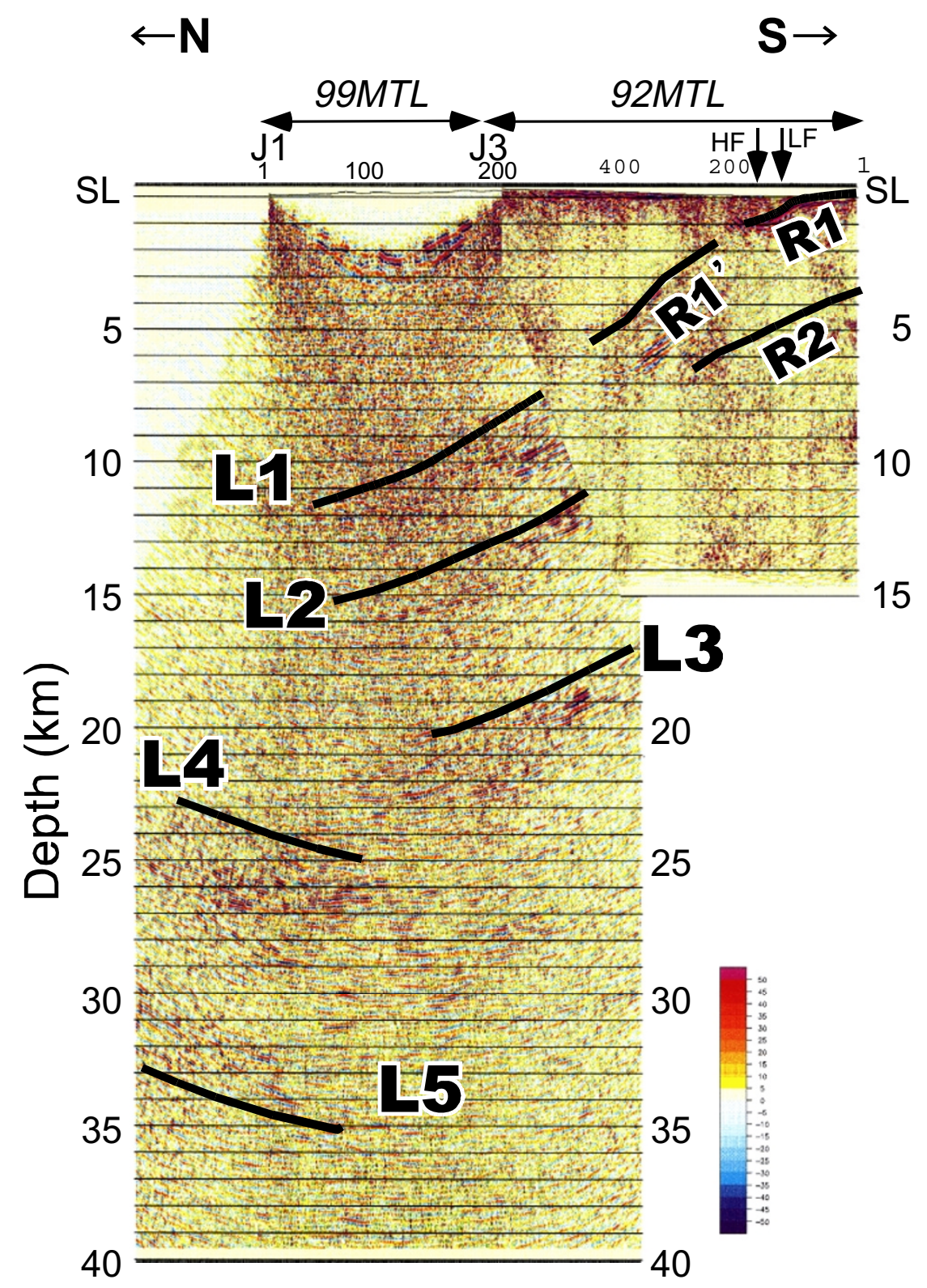

Fig. 6. Integrated depth section (migrated). Vertical axis denotes elevation and depth (km). No vertical exaggeration.

sponds to a velocity boundary jumping from 6.6 to $7.8 \mathrm{~km} / \mathrm{s}$. This suggests that the laminated zone between L4 and L5 is the lower crust, and that L5 is the Moho.

The crustal structure beneath east Shikoku interpreted from the studies of this experiment (99MTL), 92MTL (Ito et al., 1996) and Kurashimo et al. (2002) is shown in Fig. 7. The MTL is well defined from the surface to about $12 \mathrm{~km}$ depth beneath the northern end of the line (Fig. 6). It dips about $45^{\circ}$ northward from the surface to about $7 \mathrm{~km}$ depth, with the dip decreasing toward the northern end of the seismic reflection line. The Sambagawa belt is thus, overlain by the Ryoke belt. This interpretation is supported by the petrological evidence that the Setouchi volcanic rocks on the Ryoke belt include the fragments of the Sambagawa metamorphic rocks as xenoliths (Komatsu, 1996). Based on the result of 92MTL, Ito et al. (1996) have already proposed that the MTL is not vertical, but dips gently northward. This experiment confirms that interpretation.
Because we interpreted that the Northern Shimanto subbelt existed below L2, we think that L2 and R2 are deeper extensions of BTL (Fig. 7). The AF is also interpreted as extending down to the L3.

\section{Discussion}

As previous seismic refraction studies in Southwest Japan could not link deep crustal structure to the surface geology, our experiment using a dense receiver and sparse shot technique is the first to successfully relate deep to shallow structures. Although the possibility is not excluded that the reflections may come from the sides of the profile, because the area has a clear zonal arrangement and consistent strikes of the parallel fault zones, we suggests that reflectors dip in the same direction as the profile, which is perpendicular to the strike. Thus, we conclude that the origins of the major deep reflections on our seismic reflection line (L1, L2 and L3) are the major boundary faults (MTL, BTL and AF, re- 
Osaka Group

Setouchi Volcanic Rocks (Sv)

Izumi Group (Iz)

Ryoke Granite (Ry)
Sambagawa Belt (Sm)

Chichibu Belt (Ch)

\section{Shimanto Belt}

Northern Shimanto Subbelt (N-Sh)

Southern Shimanto Subbelt (S-Sh)

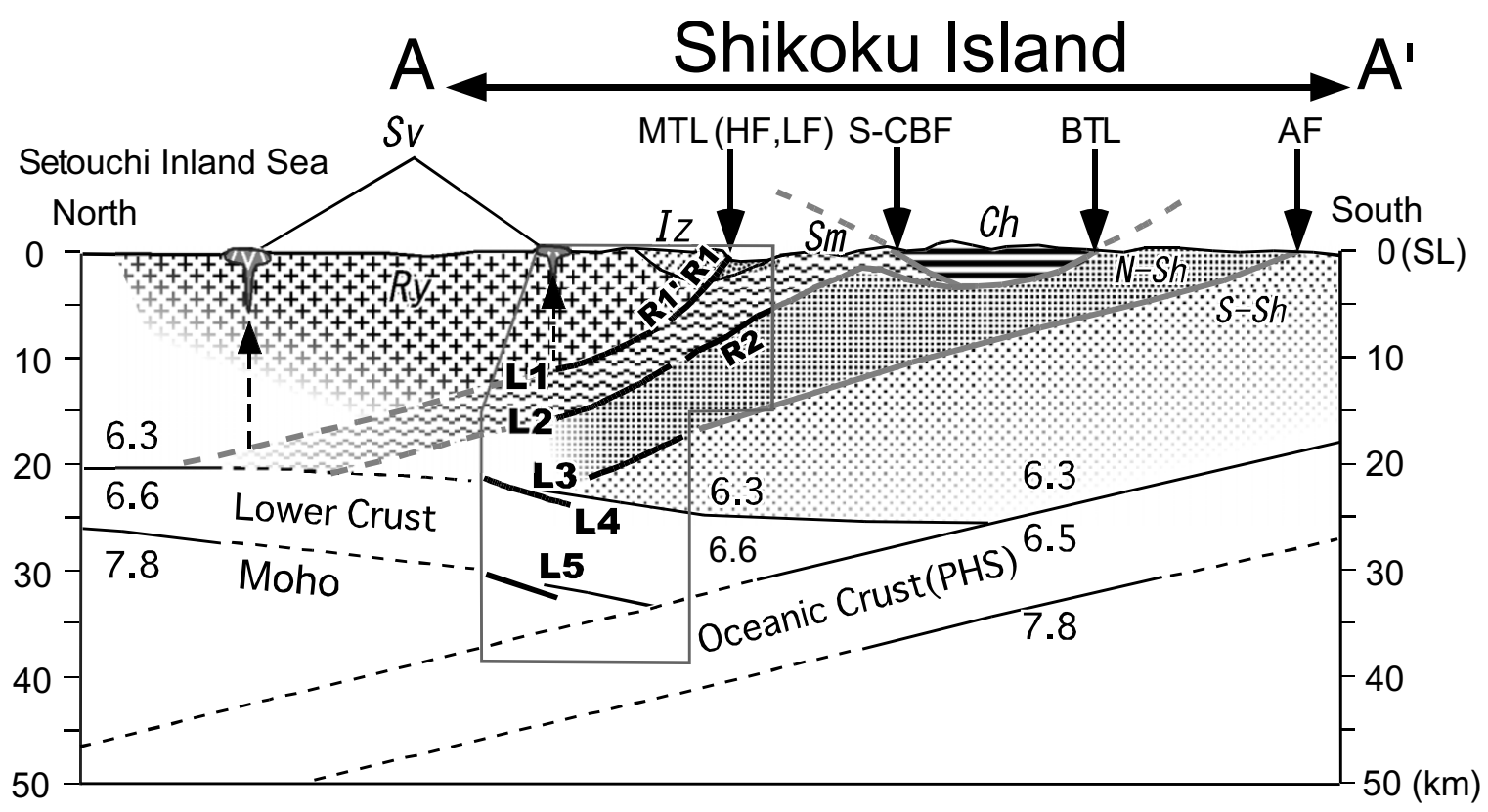

Fig. 7. Interpretation of the subsurface structure of eastern Shikoku. The polygon corresponds to Fig. 6. Ry: Ryoke Belt, Iz: Izumi group, Sm: Sambagawa Belt, Ch: Chichibu Belt, N-Sh: Northern Shimanto Subbelt; S-Sh, Southern Shimanto Subbelt. Sv: Setouchi volcanic rocks. The arrow on the dotted line indicates the rising process of the Setouchi volcanic rocks. Lower crust, Moho, and Oceanic Crust (PHS) beneath the Shikoku Island and the Setouchi Inland Sea are after Kurashimo et al. (2002). Oceanic Crust (PHS) beneath Shikoku Island is after Kodaira et al. (2000). No vertical exaggeration.

spectively) in southwestern Japan. The results of our experiment also indicate that the single-fold technique can be an effective means of probing the deep crust while substantially reducing survey costs.

We suggest that three factors were essential to the success of our experimental work. First, the receiver interval was sufficiently small to provide horizontal resolution that was able to detect deep reflectors. Sub-sampled data (Fig. 8) show that the dominant reflectors would not have been identified if the interval were as large as $500 \mathrm{~m}$, a standard interval for refraction/wide-angle reflection profiling. Second, we suspect that the relatively simple crustal structure, characterized by homoclinally dipping reflectors, contributed to the success of our experiment. If the crustal structure were more complex, enhancement of data quality by CMP stacking would be indispensable. Third, the near-surface geology lacked factors that often degrade data quality. Along the seismic line only a thin weathering layer covers fresh granite (Ryoke granite) or consolidated sedimentary rocks (Izumi Group). These materials reduce the attenuation of seismic waves near the shot points and receivers, and minimize generation of the surface waves that often obscure deep reflectors.

Thus, the effectiveness of the dense receiver and sparse shot technique method may depend on both deep structures and surface geology, and may not be applicable everywhere. It is necessary to repeat this type of experiment in other prospective areas having similar conditions to evaluate the applicability of cost-effective, single-fold imaging.

Acknowledgments. This experimental work was carried out in conjunction with the JAMSTEC's research project, and J1 (500 kg) shot was provided by JAMSTEC. We express our deep appreciation to JAMSTEC for giving us the opportunity to use the shot for our experiment. We are very grateful to Prof. L. Brown of Cornell University and Prof. D. Okaya of University of Southern California for their discussions and critical readings.

\section{References}

Fuis, G., A. Levander, J. Lutter, S. Wissinger, E. Moore, and N. Christensen, Seismic images of the Brooks Range, Arctic Alaska, reveal crustal-scale duplexing, Geology, 23, 65-68, 1995.

Geological Survey of Japan, Geology and mineral resources of Japan, Geological Survey of Japan, 430 p., 1977.

Geological Survey of Japan (ed.), Geological Map of Japan 1:1000000, 3rd Edition, CD-ROM Version. Digital Geoscience Map G-1, Geological Survey of Japan, 1995.

Hasegawa, S., Large-scale rock slides and Quaternary faulting along the Median Tectonic Line on the southern foot of the Sanuki Range in Shikoku, Southwest Japan, The Memoirs of the Geological Society of Japan, 40, 143-170, 1992 (in Japanese with English abstr.).

Isozaki, Y., Anatomy and genesis of a subduction-related orogen; a new view of geotectonic subdivision and evolution of the Japanese Islands, The Island Arc, 5, 289-320, 1996. 


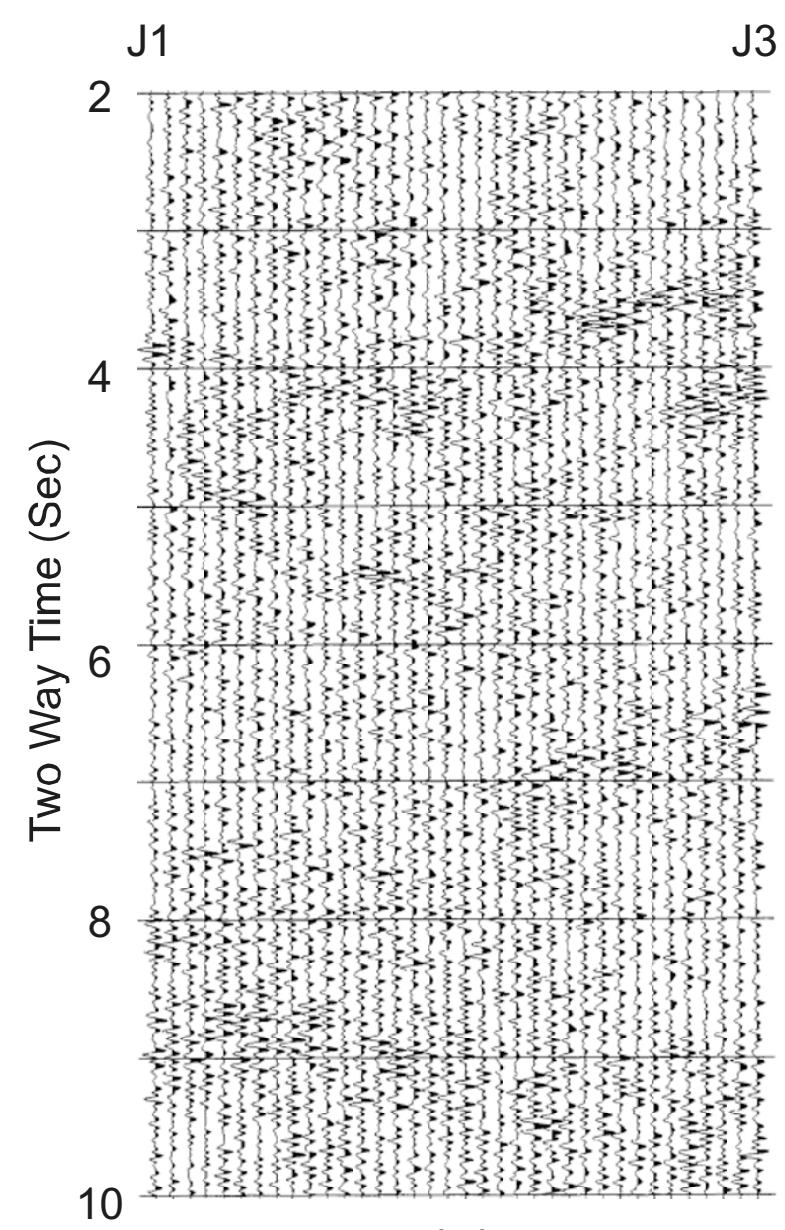

(a)
J3 J1

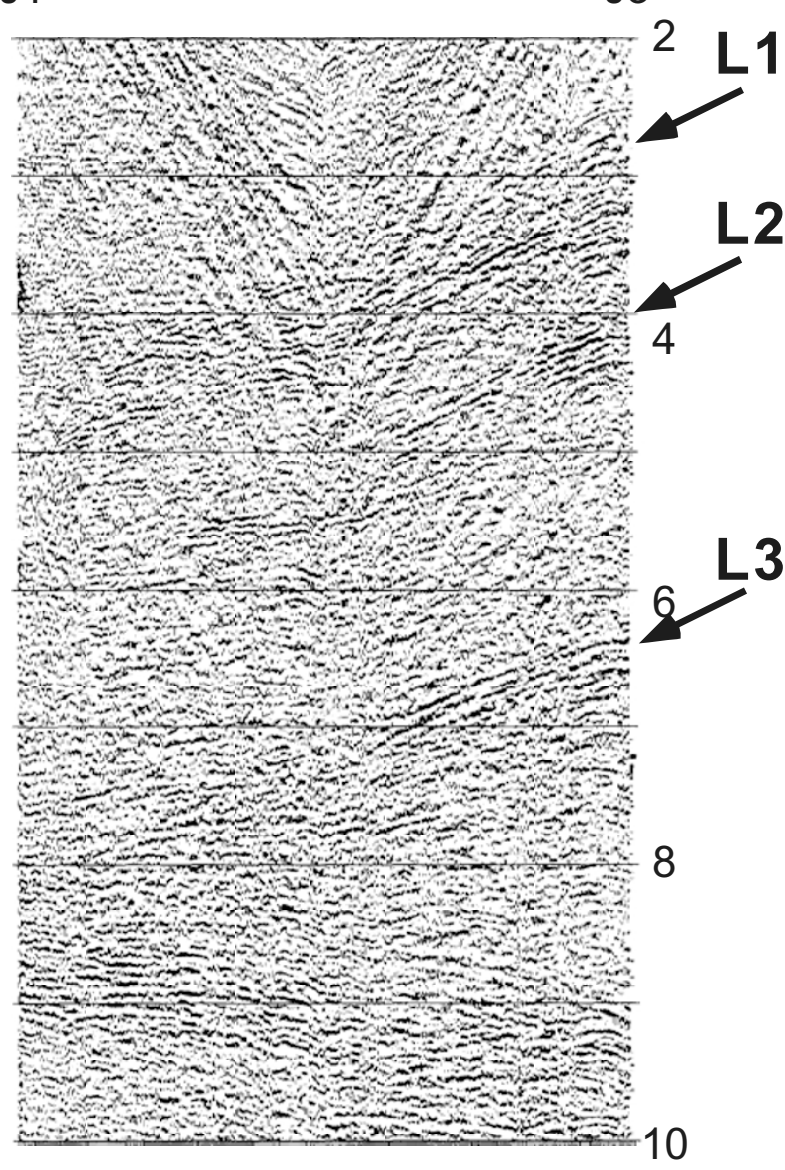

(b)

Fig. 8. Comparison of horizontal resolution based on the receiver-station interval. (a) Single-fold section (before NMO) corresponding to 500-m station interval created using every 10 th trace of the original data. (b) Original single-fold section (50-m station interval). Note clarity of reflections in (b).

Ito, T., T. Ikawa, S. Yamakita, and T. Maeda, Gently north-dipping Median Tectonic Line (MTL) revealed by recent seismic reflection studies, southwest Japan, Tectonophysics, 264, 51-63, 1996.

Kasahara, K., S. Yamakita, T. Ito, T. Kawamura, T. Iwasaki, and T. Ikawa, Seismic reflection profilings from the Median Tectonic Line (MTL) to the accretionary complexes, Kii Peninsula, southwest Japan, Abstract of 9th International Symposium on Deep Seismic Profiling of the Continents and Their Margins, 70, 2000.

Katto, J., Geology and mineral resources of Kochi Prefecture, Kochi Prefecture, 1961 (in Japanese).

Kawamura, T., E. Kurashimo, M. Shinohara, N. Tsumura, T. Ito, T. Miyauchi, H. Sato, and T. Ikawa, Detection of seismic scatterers and their geological interpretation around an active fault: the Median Tectonic Line (MTL), northwestern Kii Peninsula, Japan, Zisin, 54, 233-249, 2001 (in Japanese with English abstr.).

Klemperer, S., A. Hauge, E. Hauser, J. Oliver, and C. Potter, The Moho in the northern Basin and Range Province, Nevada, along the COCORP 40 degrees N seismic-reflection transect, Geological Society of America Bulletin, 97, 603-618, 1986.

Kodaira, S., N. Takahashi, A. Nakanishi, S. Miura, and Y. Kaneda, Subducted seamount imaged in the rupture zone of the 1946 Nankaido Earthquake, Science, 289, 104-106, 2000.

Komatsu, M., The generation of extremely high temperature zones in the deep crust beneath the Miocene Setouchi volcanic province, Southwest Japan, Report on Grant-in-Aid for Scientific General Research (A), p. 158, 1996 (in Japanese).

Kurashimo, E., M. Tokunaga, N. Hirata, T. Iwasaki, S. Kodaira, Y. Kaneda, K. Ito, R. Nishida, S. Kimura, and T. Ikawa, Geometry of the subducting Philippine Sea plate and the crustal and upper mantle structure beneath the Eastern Shikoku Island revealed by seismic refraction/wide-angle reflection profiling, Zisin, 54, 489-505, 2002 (in Japanese with English abstr.)

Mizuno, K., A. Okada, A. Sangawa, and F. Shimizu, Explanatory text of strip map of the Median Tectonic Line Active Fault System in Shikoku, Japan, scale 1:25000, Tectonic Map Series, 8, Geological Survey of Japan, 63 p., 1993 (in Japanese with English abstr.).

Murata, A., Large Decke structures and their formative process in the Sambagawa-Chichibu, Kurosegawa and Sambosan terrains, southwest Japan, Journ. of Fac. Sci. Univ. Tokyo. Sec. II, 20, 383-424, 1982.

Taira, A., T. Byrbem, and J. Ashi, Photographic Atlas of an Accretionary Prism, in Geologic Structures of the Shimanto Belt, Japan, Univ. of Tokyo Press, Tokyo, 124 p., 1992

Tatsumi, Y., N. Ishikawa, K. Anno, K. Ishizaka, and T. Itaya, Tectonic setting of high-Mg andesite magmatism in the SW Japan arc-K-Ar chronology of the Setouchi volcanic belt, Geophysical Journal International, 144, 625-631, 2001.

Tsukuda, E., A. Sangawa, and Y. Kinugasa, Neotectonic Map, 1:500000 Neotectonic Map, Sheet 8, Kochi, Geological Survey of Japan, 1982 (in Japanese).

Yoshikawa, S., Y. Iwasaki, T. Ikawa, and H. Yokota, Geological structure of the MTL in west Wakayama by reflection seismic study, The Memoirs of the Geological Society of Japan, 45, 177-186, 1992 (in Japanese with English abstr.)

Yusa, Y., K. Takemura, K. Kitaoka, K. Kamiyama, S. Horie, I. Nakagawa, Y. Kobayashi, A. Kubotera, Y. Sudo, T. Ikawa, and M. Asada, Subsurface structure of Beppu Bay (Kyushu, Japan) by seismic reflection and gravity survey, Zisin, 45, 199-212, 1992 (in Japanese with English abstr.).

T. Kawamura (e-mail: tkawa@eri.u-tokyo.ac.jp), M. Onishi, E. Kurashimo, T. Ikawa, and T. Ito 